Special Collection: Sensing and Monitoring Research Group, SAMJ

\title{
Year-to-year blooming phenology observation using time-lapse digital camera images
}

\author{
Shin NAGAI*, ${ }^{\dagger}$, Shinpei YoshITAKE**, Tomoharu InOUE*, Rikie SUZUKI*, \\ Hiroyuki MURAOKA**, Kenlo Nishida NASAHARA***, and Taku M SAITOH** \\ $\left(\begin{array}{c}* \text { Department of Environmental Geochemical Cycle Research, Japan Agency for Marine-Earth Science and } \\ \text { Technology (JAMSTEC), 3173-25 Showa-machi, Kanazawa-ku, Yokohama 236-0001, Japan } \\ * * \text { River Basin Research Center, Gifu University, 1-1 Yanagido, Gifu 501-1193, Japan } \\ * * * \text { Faculty of Life and Environmental Sciences, University of Tsukuba, 1-1-1 Tennodai, Tsukuba 305-8572, } \\ \text { Japan }\end{array}\right)$
}

\begin{abstract}
Long-term continuous phenological observation of cherry tree blooming is an important and challenging task in the evaluation of year-to-year weather and climate changes in spring in Japan. Here, (1) we performed daily field observations with a time-lapse digital camera in a deciduous broad-leaved forest in Japan from January 2004 to December 2013; and (2) we detected year-to-year variations in the blooming phenology of Prunus sargentii by visual inspection of the images and by image analysis. We found that (1) the red digital numbers (i.e., the digital intensity values of the red pixels; $\mathrm{DN}_{\mathrm{R}}$ ) extracted from the time-lapse digital camera images tended to peak in full bloom; and (2) the green excess index (GEI) (based on the red, green, and blue digital numbers) tended to be lowest in full bloom. These results indicate that $\mathrm{DN}_{\mathrm{R}}$ and GEI are useful for detecting the timing of full bloom in $P$. sargentii.
\end{abstract}

Key words: Bio-meteorological observation, Blooming phenology, Cherry tree, Climate change, Time-lapse digital camera image.

\section{Introduction}

Over the past few decades, the blooming dates of Prunus mume and Prunus yedoensis in Japan have

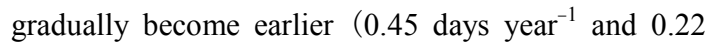

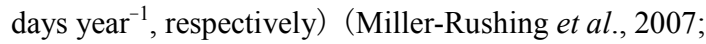
Shimizu and Omasa, 2010). Blooming date is strongly correlated with year-to-year variations in air temperature during a period of 1 or 2 months before blooming (Omoto and Aono, 1989; Miller-Rushing et al., 2007; Ibáñez et al., 2010), and it is spatially distributed along gradients in latitude and local climate (Nakashima et

Received; September 2, 2013.

Accepted; June 25, 2014.

${ }^{\dagger}$ Corresponding Author: nagais@jamstec.go.jp

DOI: 10.2480/agrmet.D-13-00021 al., 1997; Shimizu and Omasa, 2010). Year-to-year variations in blooming date are useful for reconstructing data related to changes in climate that have occurred since the 9th century (Aono and Kazui, 2008); they also affect the phenology of pollinators (Kudo et al., 2004). In addition, knowledge of flowering phenology enables us to enjoy the changing seasons by informing us about periods when floral displays will be at their best (Maruoka and Itoh, 2009), and thus it has a positive economic effect in terms of tourism (Murata et al., 2012). Therefore, large-scale, long-term, continuous phenological observation and forecasting of blooming dates are important, although challenging (Omoto and Aono, 1989; Aono and Omoto, 1990; Aono and Moriya, 2003; Maruoka and Itoh, 2009).

In previous studies, long-term in situ phenological data identified from index trees by expert observers 
have been used to evaluate year-to-year variations in blooming phenology (Miller-Rushing et al., 2007; Ibáñez et al., 2010; Shimizu and Omasa, 2010). However, gathering data in this manner has several problems, including lack of objectivity (Richardson et al., 2007) and the need for intensive labor (Richardson et al., 2007). To solve these problems, we (Nagai et al., 2013) have suggested a biometeorological observation method that uses a time-lapse digital camera and an automatic weather station (AWS), and we have used the method to examine the relationship between yearto-year variations in leaf expansion and defoliation and daily air temperature in a cool-temperate deciduous broad-leaved forest in Japan (Nagai et al., 2013). Time-lapse digital cameras have been installed not only at ecological study sites (Richardson et al., 2007; Ahrends et al., 2009; Nagai et al., 2013) but also in public areas, such as national parks, tourist sites, and along highways (Graham et al., 2010; Ide and Oguma, 2010; Morris et al., 2013). The success of these studies suggests that spatiotemporal variability in blooming phenology can be detected over wide areas using timelapse digital camera images at multiple points. Nijland et al. (2013) showed that time-lapse digital camera images were useful for detecting blooming phenology in an alpine meadow. However, the detection of yearto-year variations in blooming phenology has not yet been sufficiently investigated.

Accordingly, we examined year-to-year variations in the blooming phenology of Prunus sargentii Rehder in Japan by performing daily field observations with a time-lapse digital camera in a deciduous broad-leaved forest from January 2004 to December 2013. Our aim was to provide robust evidence of the usefulness of long-term continuous time-lapse digital camera images for detecting year-to-year variations in blooming phenology.

\section{Materials and Methods}

\subsection{Study site}

Our study site was located at Takayama in central Japan (site TKY; $36^{\circ} 08^{\prime} 46^{\prime \prime} \mathrm{N}, 137^{\circ} 25^{\prime} 23^{\prime \prime} \mathrm{E}, 1430 \mathrm{~m}$ above sea level [a.s.1.]), in a 60-year-old, cooltemperate, deciduous broad-leaved forest. The site is part of the AsiaFlux network (http://asiaflux.net) and JaLTER (the Japan Long-Term Ecological Research network; http://www.jalter.org). The dominant canopy species are Quercus crispula Blume, Betula ermanii
Cham., and Betula platyphylla Sukatchev var. japonica Hara. The height of the forest canopy ranges from 13 to $20 \mathrm{~m}$. The density of $P$. sargentii is 28 trees $\mathrm{ha}^{-1}$. The forest floor is covered by the evergreen dwarf bamboo Sasa senanensis Rehder, which reaches a height of 1 to $2 \mathrm{~m}$ (Ohtsuka et al., 2005). From 1996 to 2012 , the annual mean air temperature and annual average precipitation at the nearby site (about $500 \mathrm{~m}$ south of TKY) averaged $7.1{ }^{\circ} \mathrm{C}$ and $2122 \mathrm{~mm}$, respectively. The snow season begins in early December and ends in late April.

\subsection{Camera images}

At TKY, we installed an automatic digital fisheye camera system, consisting of Coolpix 4300 or 4500 digital cameras (Nikon, Tokyo, Japan), an FC-E8 fisheye lens (Nikon), and an SPC31A controller (Hayasaka Rikoh, Sapporo, Japan), at the top of a canopy access tower (18 m above ground level; Nishida, 2007). The camera was pointed downward and captured hemispherical images of the forest canopy every 90 min during daylight hours and stored them in JPEG format. Image size was set to $2272 \times 1704$ pixels and exposure to "automatic." The white balance was set to "sunny," except from 29 August 2008 to 16 June 2009, when it was set to "automatic." The field of view changed by $180^{\circ}$ on 26 March 2013 because we changed to a digital camera. We used the images obtained daily at 12:00 local time from 1 January 2004 to 31 December 2013. Saitoh et al. (2012) reported that images obtained daily at 12:00 local time are suitable for avoiding the effect of the diurnal cycle of solar altitude on image analysis. Camera images obtained on rainy, snowy, or foggy days were discarded. The camera images were provided by PEN (the Phenological Eyes Network) and are publicly available on the Internet at http://www.pheno-eye.org.

\subsection{Image analysis}

First, we detected the full-bloom period for each year by visually inspecting the images. Canopy surface images dated 5 days before the first date of full bloom, the first date of full bloom, the last date of full bloom, and 5 days after the last date of full bloom are shown in Figure 1. Second, we calculated the average values of the red, green, and blue "digital numbers" $\left(\mathrm{DN}_{\mathrm{RGB}}\right)$ in the target area (see panel [II] in Fig. 1[a]) at a daily time step using the time-lapse digital camera images. Changes in $\mathrm{DN}_{\mathrm{RGB}}$ values can be expected in spring because $P$. sargentii blooms with pink flowers and has 
(a)

(b)

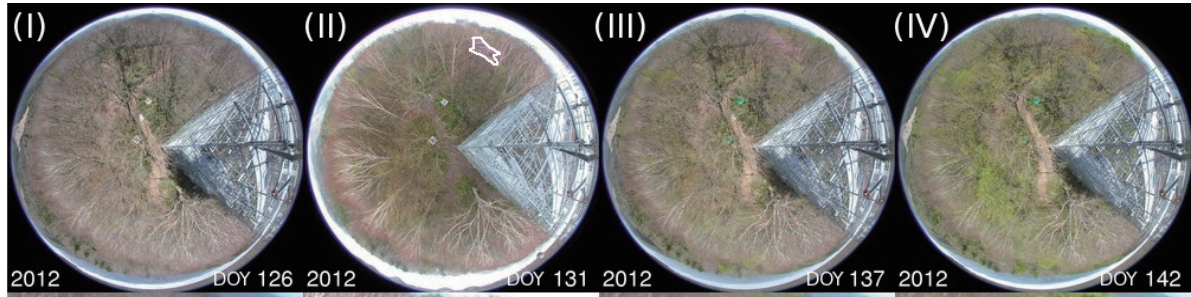

Fig. 1. (a) Typical time-lapse digital camera images taken of the canopy surface in 2012 (I) 5 days before the first day of full bloom (day of year: DOY); (II) on the first day of full bloom; (III) on the last day of full bloom; and (IV) 5 days after the last day of full bloom. (b) Zoom views of Prunus sargentii at the times mentioned above. Canopy area analyzed for $\mathrm{DN}_{\mathrm{RGB}}$ values is shown by the white line in Figure (a) - (II) .

a flush of reddish green leaves. The dynamic range of $\mathrm{DN}_{\mathrm{RGB}}$ was 256. Third, we calculated $\mathrm{DN}_{\mathrm{R}}$ (red), $\mathrm{DN}_{\mathrm{G}}$ (green), and $\mathrm{DN}_{\mathrm{B}}$ (blue) as percentages (denoted as $\mathrm{rR}, \mathrm{rG}$, and $\mathrm{rB}$ ) of the total $\mathrm{DN}$ :

$$
\begin{aligned}
& \mathrm{rR}=100 \times \mathrm{DN}_{\mathrm{R}} /\left(\mathrm{DN}_{\mathrm{R}}+\mathrm{DN}_{\mathrm{G}}+\mathrm{DN}_{\mathrm{B}}\right), \\
& \mathrm{rG}=100 \times \mathrm{DN}_{\mathrm{G}} /\left(\mathrm{DN}_{\mathrm{R}}+\mathrm{DN}_{\mathrm{G}}+\mathrm{DN}_{\mathrm{B}}\right), \\
& \mathrm{rB}=100 \times \mathrm{DN}_{\mathrm{B}} /\left(\mathrm{DN}_{\mathrm{R}}+\mathrm{DN}_{\mathrm{G}}+\mathrm{DN}_{\mathrm{B}}\right) .
\end{aligned}
$$

Finally, we calculated the green excess index (GEI; Richardson et al., 2007) and the HUE values in the hue, saturation, and value (hexagonal cone color model; Smith, 1978; Takagi and Shimoda, 2004), which have been examined in many previous studies (Richardson et al., 2007; Ide and Oguma, 2010; Mizunuma et al., 2011; Saitoh et al., 2012; Morris et al., 2013; Nagai et al., 2013; Nijland et al., 2013):

$$
\begin{aligned}
& \mathrm{GEI}=\left(\mathrm{DN}_{\mathrm{G}}-\mathrm{DN}_{\mathrm{R}}\right)+\left(\mathrm{DN}_{\mathrm{G}}-\mathrm{DN}_{\mathrm{B}}\right) \text {, } \\
& \mathrm{HUE}=\left(\mathrm{DN}_{\mathrm{B}}-\mathrm{DN}_{\mathrm{R}}\right) /\left(\mathrm{DN}_{\max }-\mathrm{DN}_{\min }\right) \times 60 \\
& +120 \text { if } \mathrm{DN}_{\mathrm{G}}=\mathrm{DN}_{\max } \\
& \mathrm{HUE}=\left(\mathrm{DN}_{\mathrm{R}}-\mathrm{DN}_{\mathrm{G}}\right) /\left(\mathrm{DN}_{\max }-\mathrm{DN}_{\text {min }}\right) \times 60 \\
& +240 \text { if } \mathrm{DN}_{\mathrm{B}}=\mathrm{DN}_{\max } \\
& \mathrm{HUE}=\left(\mathrm{DN}_{\mathrm{G}}-\mathrm{DN}_{\mathrm{B}}\right) /\left(\mathrm{DN}_{\max }-\mathrm{DN}_{\min }\right) \times 60 \\
& +360 \text { if } \mathrm{DN}_{\mathrm{G}}<\mathrm{DN}_{\mathrm{B}} \\
& \mathrm{HUE}=\left(\mathrm{DN}_{\mathrm{G}}-\mathrm{DN}_{\mathrm{B}}\right) /\left(\mathrm{DN}_{\max }-\mathrm{DN}_{\min }\right) \times 60 \\
& \text { otherwise, }
\end{aligned}
$$

Table 1. Summary of the first date of full bloom (FDFB; DOY) and last date of full bloom (LDFB; DOY).

\begin{tabular}{ccccccccccc}
\hline Year & 2004 & 2005 & 2006 & 2007 & 2008 & 2009 & 2010 & 2011 & 2012 & 2013 \\
\hline FDFB & 123 & 125 & 132 & 133 & 126 & 127 & 130 & 138 & 131 & 134 \\
LDFB & 129 & 133 & 139 & 136 & 133 & 130 & 137 & 140 & 137 & 135 \\
\hline
\end{tabular}

DOY: day of year where $\mathrm{DN}_{\max }$ is the maximum value of $\mathrm{DN}_{\mathrm{R}}, \mathrm{DN}_{\mathrm{G}}$, and $\mathrm{DN}_{\mathrm{B}}$, and $\mathrm{DN}_{\text {min }}$ is the minimum value of $\mathrm{DN}_{\mathrm{R}}, \mathrm{DN}_{\mathrm{G}}$, and $\mathrm{DN}_{\mathrm{B}}$. Richardson et al. (2007) and Mizunuma et al. (2011) indicated that GEI and HUE are useful camera-based indices for detecting spring phenology (i.e., from bud dormancy to leaf expansion) more clearly than with $\mathrm{DN}_{\mathrm{RGB}}$ and $\mathrm{rR}, \mathrm{rG}$, and $\mathrm{rB}$.

\section{Results}

\subsection{Visual inspection}

Year-to-year variations in the first date of full bloom and the last date of full bloom, as detected by visual inspection of the images, are summarized in Table 1. The average first date of full bloom was DOY 130, and the average last date of full bloom was DOY 135. The last date of full bloom was the earliest in 2004 (DOY 123) and the latest in 2011 (DOY 138). The period of full bloom was the longest in 2005 (9 days) and the shortest in 2013 ( 2 days).

\section{2 $\mathrm{DN}_{\mathrm{RGB}}, \mathrm{rR}, \mathrm{rG}, \mathrm{rB}, \mathrm{GEI}$, and HUE}

We examined the seasonal patterns of $\mathrm{DN}_{\mathrm{RGB}}$, $\mathrm{rR}$, rG, rB, GEI, and HUE in 2012 (Fig. 2). The seasonal patterns of all parameters for other years were almost 
the same as those for 2012. The results are presented below for four periods (bud dormancy, flowering, leaf expansion, and leaf fall).

Bud dormancy period. All parameters had constant values early on (there was snow cover until DOY 110), although $\mathrm{DN}_{\mathrm{RGB}}$ and HUE fluctuated. From DOY 110 to $120, \mathrm{DN}_{\mathrm{RGB}}$ rapidly increased as the snow melted, whereas $\mathrm{rR}, \mathrm{rG}, \mathrm{rB}, \mathrm{GEI}$, and HUE remained nearly constant.
Flowering period. After DOY $120, \mathrm{DN}_{\mathrm{R}}$ and $\mathrm{rR}$ increased slightly, and then peaked at DOY 131 and 140, respectively. These dates corresponded to the start of full bloom and 3 days after the last date of full bloom, respectively. The maximum $\mathrm{rR}$ value indicated the detection of the flush of reddish green leaves, with their remaining reddish calyces. In contrast, GEI decreased slightly and then reached its lowest value at DOY 131. This date corresponded to the start of full

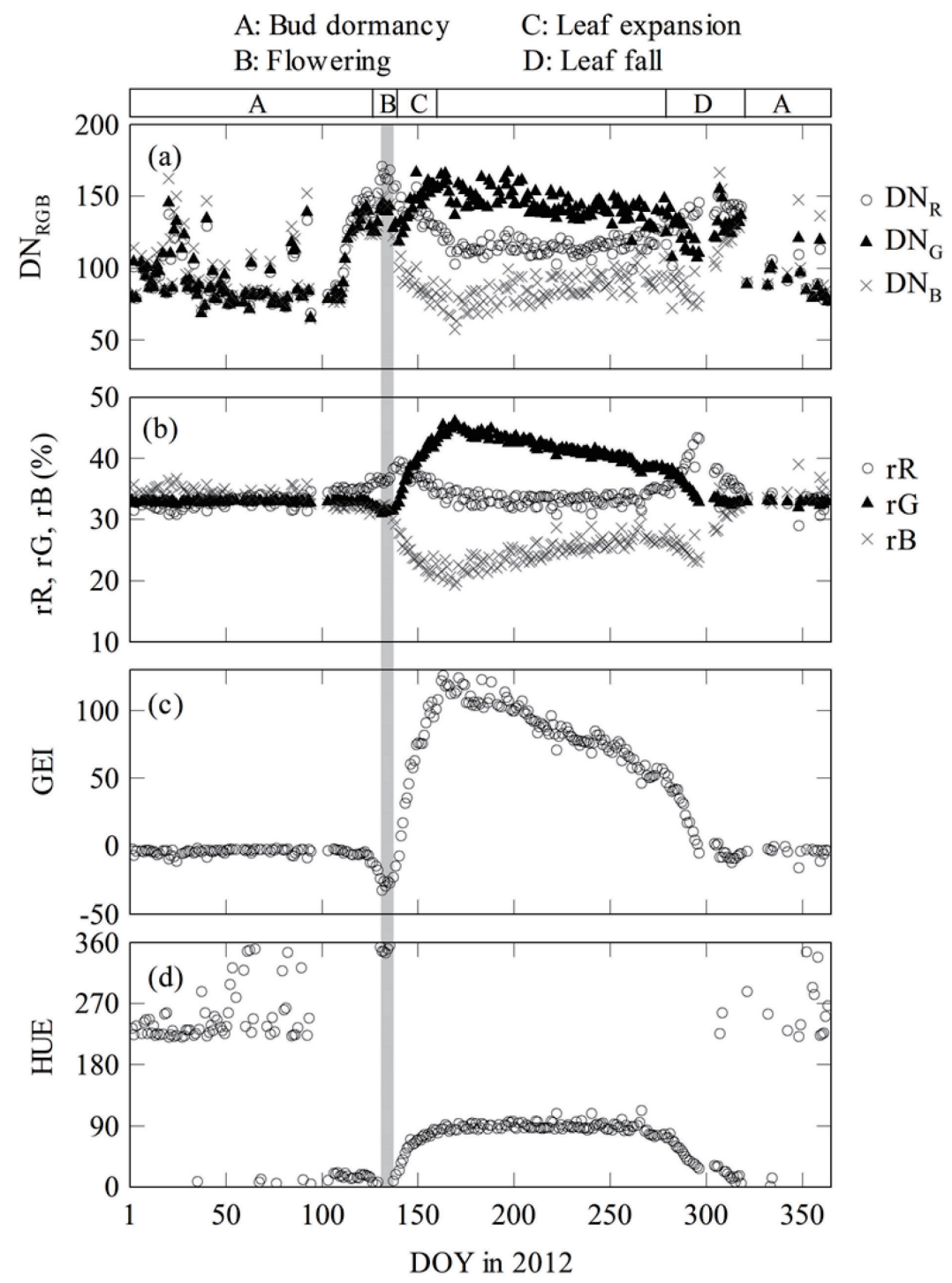

Fig. 2. Seasonal changes in (a) $\mathrm{DN}_{\mathrm{RGB}}$; (b) $\mathrm{rR}$, rG, and rB; (c) GEI; and (d) HUE in 2012. Gray band shows time of full bloom. (A) bud dormancy, (B) flowering, (C) leaf expansion, and (D) leaf fall periods are shown at the top of figure. 


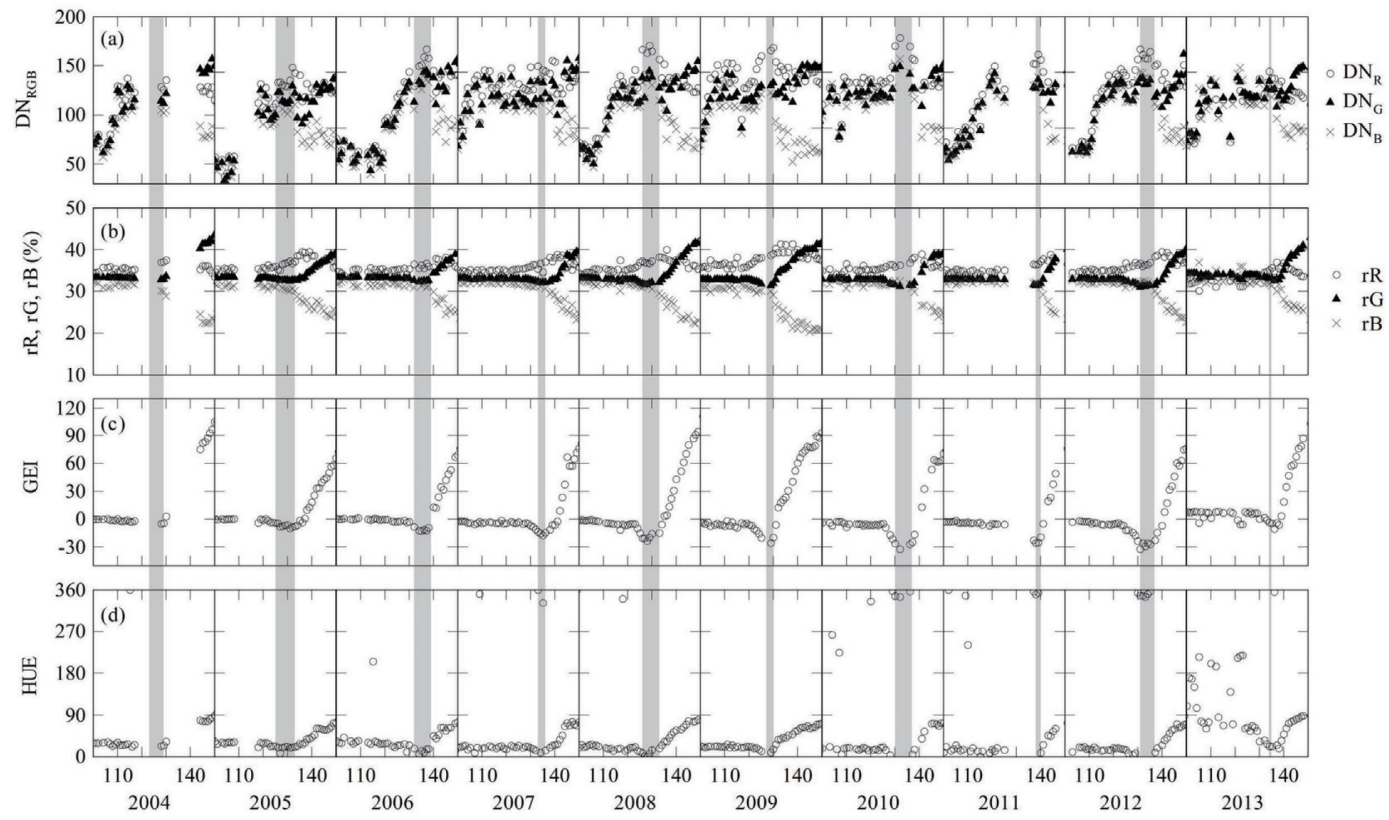

Fig. 3. Seasonal changes in (a) $\mathrm{DN}_{\mathrm{RGB}}$; (b) $\mathrm{rR}, \mathrm{rG}$, and $\mathrm{rB}$; (c) GEI; and (d) HUE from DOY 100 to 150 in each year. Times of full bloom are shown by the gray bands.

bloom.

Leaf expansion period. From DOY 140 to $160, \mathrm{DN}_{\mathrm{G}}$, $\mathrm{rG}$, GEI, and HUE rapidly increased with leaf expansion, whereas $\mathrm{DN}_{\mathrm{R}}, \mathrm{DN}_{\mathrm{B}}, \mathrm{rR}$, and $\mathrm{rB}$ rapidly decreased.

Leaf fall period. From DOY 280 to $300, \mathrm{DN}_{\mathrm{G}}, \mathrm{DN}_{\mathrm{B}}$, $\mathrm{rG}, \mathrm{rB}, \mathrm{GEI}$, and HUE decreased with leaf coloring and defoliation, whereas $\mathrm{DN}_{\mathrm{R}}$ and $\mathrm{rR}$ increased and then peaked. From DOY 300 to $320, \mathrm{DN}_{\mathrm{G}}, \mathrm{DN}_{\mathrm{B}}$ and $\mathrm{rB}$ increased with defoliation, whereas $\mathrm{rR}$ decreased.

We also plotted the seasonal patterns of $\mathrm{DN}_{\mathrm{RGB}}, \mathrm{rR}$, $\mathrm{rG}, \mathrm{rB}, \mathrm{GEI}$, and HUE from DOY 100 to 150 (including the flowering period) for each year (Fig. 3). Yearto-year variations in the day of the year on which we observed the spring peaks of $\mathrm{DN}_{\mathrm{R}}\left(\mathrm{DN}_{\mathrm{RSpring} \max }\right)$ and $\mathrm{rR}\left(\mathrm{rR}_{\text {Spring } \max }\right)$ and the spring minimum of GEI $\left(\mathrm{GEI}_{\text {Spring min }}\right)$ are summarized in Table 2. Almost all the dates on which we observed $\mathrm{DN}_{\mathrm{RSpring}} \max$ and $\mathrm{GEI}_{\text {Spring min }}$ corresponded to full bloom (Fig. 3). The average last date of full bloom and the average timing of $\mathrm{DN}_{\text {RSpring max }}$ were 3.67 and 5.56 days earlier, respectively, than that of $\mathrm{rR}_{\text {Spring } \max }$.

\section{Discussion}

In disagreement with the results of previous studies in deciduous broad-leaved trees (Ahrends et al., 2009; Ide and Oguma, 2010; Mizunuma et al., 2011; Nagai et al., 2011), the seasonal patterns of $\mathrm{DN}_{\mathrm{R}}, \mathrm{rR}$, and GEI of $P$. sargentii were characterized by the following: (1) $\mathrm{DN}_{\mathrm{R}}$ tended to peak in full bloom, whereas $\mathrm{rR}$ peaked just after (i.e., 2 to 6 days after) the last date of full bloom; and (2) GEI tended to be lowest in full bloom (Figs. 2 and 3 and Table 2).

These patterns of change in $\mathrm{DN}_{\mathrm{R}}$ and $\mathrm{rR}$ can be explained in the following way. In full bloom and just after the last date of full bloom, $\mathrm{DN}_{\mathrm{R}}$ was larger than $\mathrm{DN}_{\mathrm{G}}$ and $\mathrm{DN}_{\mathrm{B}}$ because of the blooming of the pink flowers and the flush of reddish green leaves. However, the values of $\mathrm{DN}_{\mathrm{RGB}}$ - and especially $\mathrm{DN}_{\mathrm{B}}$ - just after the last date of full bloom were smaller than those in full bloom (Figs. 2 and 3) because the color of the canopy surface changed from pink to reddish green. These changes in $\mathrm{DN}_{\mathrm{RGB}}$ values caused the peak timing of $\mathrm{rR}$ to be later than that of $\mathrm{DN}_{\mathrm{R}}$. Previous studies have shown that, in deciduous broad-leaved trees (which do not bloom before leaf flush), $\mathrm{DN}_{\mathrm{R}}$ does not show a minimum or maximum value before leaf flush (Richardson et al., 2007; Mizunuma et al., 2011). Together, these findings suggest that $\mathrm{DN}_{\mathrm{R}}$ is useful for 
Table 2. Summary of date (DOY) on which we observed the maximum $\mathrm{DN}_{\mathrm{R}}$ and $\mathrm{rR}$ values $\left(\mathrm{DN}_{\mathrm{RSpring} \text { max }}\right.$ and $\mathrm{rR}_{\text {Spring max }}$ ) and the minimum GEI value (DOY 121 to $150 ; \mathrm{GEI}_{\text {Spring min }}$ ) in spring.

\begin{tabular}{cccccccccc}
\hline Year & 2005 & 2006 & 2007 & 2008 & 2009 & 2010 & 2011 & 2012 & 2013 \\
\hline $\mathrm{DN}_{\mathrm{RSpring} \mathrm{max}}$ & 132 & 137 & 139 & 129 & 130 & 132 & 139 & 131 & 134 \\
$\mathrm{rR}_{\text {Spring max }}$ & 136 & 145 & 141 & 136 & 133 & 141 & 144 & 140 & 137 \\
$\mathrm{GEI}_{\text {Spring min }}$ & 127 & 137 & 135 & 128 & 129 & 132 & 138 & 131 & 136 \\
\hline
\end{tabular}

DOY: day of year. We were not able to detect $\mathrm{DN}_{\mathrm{RSpring}_{\max },} \mathrm{rR}_{\text {Spring max }}$, and $\mathrm{GEI}_{\text {Spring min }}$ in 2004 because of insufficient data.

detecting the timing of full bloom in P. sargentii.

The pattern of change in GEI can be explained by the following. In full bloom, $\mathrm{DN}_{\mathrm{G}}$ and $\mathrm{DN}_{\mathrm{B}}$ had almost the same values, whereas $\mathrm{DN}_{\mathrm{R}}$ was larger than $\mathrm{DN}_{\mathrm{G}}$ and $\mathrm{DN}_{\mathrm{B}}$ because the canopy surface was pink. In contrast, all three $\mathrm{DN}_{\mathrm{RGB}}$ values were almost the same just before the first date of full bloom because the canopy surface, which was covered in bare branches, was brown. Just after the last date of full bloom, $\mathrm{DN}_{\mathrm{R}}$ and $\mathrm{DN}_{\mathrm{B}}$ decreased and $\mathrm{DN}_{\mathrm{G}}$ increased as the flowers began to drop and the flush of reddish green leaves began (Figs. 2 and 3). In this period, the color of the canopy surface changed from red to reddish green. This pattern of change in $\mathrm{DN}_{\mathrm{RGB}}$ values thus minimized the value of GEI in full bloom. Previous studies have shown that the value of GEI in deciduous broad-leaved trees, which do not bloom before leaf flush, is not at its lowest before leaf flush (Ahrends et al., 2009; Ide and Oguma, 2010; Mizunuma et al., 2011; Nagai et al., 2011). Nijland et al. (2013) reported that the GEI of Hedysarum alpinum was lowest at the time of blooming of the plant's pink flowers. Together, these findings suggest that the GEI is useful for detecting the timing of full bloom in P. sargentii.

\section{Conclusion}

Our case study of $P$. sargentii revealed that (1) year-to-year variations in blooming phenology can be detected by visual inspection and scientific analysis of long-term continuous time-lapse digital camera images; and (2) $\mathrm{DN}_{\mathrm{R}}$ and GEI are useful for detecting the timing of full bloom in $P$. sargentii. Unattended longterm continuous observations of various species using time-lapse digital cameras in remote regions, where there are few weather stations (Ueno et al., 2013) and it is difficult to make frequent in situ phenological observations of index trees because of poor accessibility, may provide important biometeorological information as an indicator of year-to-year variations in weather and of climate change in spring. However, time-lapse digital cameras set up to search for tree shoots are also required to reduce the quantitative difference between the in situ phenological data identified on index trees by expert observers and the data obtained by time-lapse digital cameras (like ours) looking at entire tree stands.

\section{Acknowledgments}

We wish to thank K. Kurumado, I. Tamagawa, H. M. Noda, and all the members of the Takayama community for their help in the field. We also thank the editor and the two anonymous reviewers for their kind and constructive comments. S. Nagai, R. Suzuki, and T. Inoue are supported by the Environment Research and Technology Development Fund (S-9) of the Ministry of the Environment of Japan. S. Nagai is supported by KAKENHI (24710021; Grant-in-Aid for Young Scientists B, from the Japan Society for the Promotion of Science).

\section{References}

Ahrends, H. E., Etzold, S., Kutsch, W. L., Stoeckli, R., Bruegger, R., Jeanneret, F., Wanner, H., Buchmann, N., and Eugster, W., 2009: Tree phenology and carbon dioxide fluxes: use of digital photography for process-based interpretation at the ecosystem scale. Climatic Research, 39, 261-274.

Aono, Y., and Omoto, Y., 1990: Estimation of blooming date for Prunus yedoensis using DTS combined with Chill-unit accumulations (in Japanese with English abstract). Journal of Agricultural Meteorology, 45, 243-249. 
Aono, Y., and Moriya, C., 2003: A generalized model to estimate flowering for cherry tree (Prunus yedoensis) considering both processes of endodormancy completion and development (in Japanese with English abstract). Journal of Agricultural Meteorology, 59, 165-177.

Aono, Y., and Kazui, K., 2008: Phenological data series of cherry tree flowering in Kyoto, Japan, and its application to reconstruction of springtime temperatures since the 9th century. International Journal of Climatology, 28, 905-914.

Graham, E. A., Riordan, E. C., Yuen, E. M., Estrin, D., and Rundel, P. W., 2010: Public internet-connected cameras used as a cross-continental ground-based plant phenology monitoring system. Global Change Biology, 16, 3014-3023.

Ibáñez, I., Primack, R. B., Miller-Rushing, A. J., Ellwood, E., Higuchi, H., Lee, S. D., Kobori, H., and Silander, J. A., 2010: Forecasting phenology under global warming. Philosophical Transactions of the Royal Society B, 365, 3247-3260.

Ide, R., and Oguma, H., 2010: Use of digital cameras for phenological observations. Ecological Informatics, 5, 339-347.

Kudo, G., Nishikawa, Y., Kasagi, T., and Kosuge, S., 2004: Does seed production of spring ephemerals decrease when spring comes early?. Ecological Research, 19, 255-259.

Maruoka, T., and Itoh, H., 2009: Impact of global warming on flowering of cherry trees (Prunus yedoensis) in Japan (in Japanese with English abstract). Journal of Agricultural Meteorology, 65, 283-296.

Miller-Rushing, A. J., Katsuki, T., Primack, R. B., Ishii, Y., Lee, S. D., and Higuchi, H., 2007: Impact of global warming on a group of related species and their hybrids: cherry tree (Rosaceae) flowering at Mt. Takao, Japan. American Journal of Botany, 94, 1470-1478.

Mizunuma, T., Koyanagi, T., Mencuccini, M., Nasahara, K. N., Wingate, L., and Grace, J., 2011: The comparison of several colour indices for the photographic recording of canopy phenology of Fagus crenata Blume in eastern Japan. Plant Ecology \& Diversity, 4, 67-77.

Morris, D. E., Boyd, D. S., Crowe, J. A., Johnson, C. S., and Smith K. L., 2013: Exploring the potential for automatic extraction of vegetation phenological metrics from traffic webcams. Remote Sensing, 5,
2200-2218.

Murata, H., Shinshi, K., Yamamoto, S., Watanabe, S., Mito, K., Suematsu, N., Nakamura, S., Murakami, S., Ishii, C., and Yamamoto, H., 2012: Exploration, multiplication, and flowering behavior in early flowering cherry trees in Minami-izu region, and their contribution to tourism resources (in Japanese). Horticultural Research, (Japan), 11, 433-438.

Nagai, S., Maeda, T., Gamo, M., Muraoka, H., Suzuki, R., and Nasahara, K. N., 2011: Using digital camera images to detect canopy condition of deciduous broad-leaved trees. Plant Ecology \& Diversity, 4, 79-89.

Nagai, S., Saitoh, T. M., Kurumado, K., Tamagawa, I., Kobayashi, H., Inoue, T., Suzuki, R., Gamo, M., Muraoka, H., and Nasahara, K. N., 2013: Detection of bio-meteorological year-to-year variation by using digital canopy surface images of a deciduous broad-leaved forest. SOLA, 9, 106-110.

Nakashima, A., Yabu, S., Nakano, S., and Nagata, H., 1997: Regional and yearly changes of flowering date in Prunus yedoensis studied for the observation by the Meteorological Agency (in Japanese with English abstract). Environmental Systems Research, 25, 7-12.

Nijland, W., Coops, N. C., Coogan, S. C. P., Bater, C. W., Wulder, M. A., Nielsen, S. E., McDermid, G., and Stenhouse, G. B., 2013: Vegetation phenology can be captured with digital repeat photography and linked to variability of root nutrition in Hedysarum alpinum. Applied Vegetation Science, 16, 317-324.

Nishida, K., 2007: Phenological Eyes Network (PEN): a validation network for remote sensing of the terrestrial ecosystems. AsiaFlux Newsletter, 21, 9-13 (http://www.asiaflux.net/).

Ohtsuka, T., Akiyama, T., Hashimoto, Y., Inatomi, M., Sakai, T., Jia, S., Mo, W., Tsuda, S., and Koizumi, H., 2005: Biometric based estimates of net primary production (NPP) in a cool-temperate deciduous forest stand beneath a flux tower. Agricultural and Forest Meteorology, 134, 27-38.

Omoto, Y., and Aono, Y., 1989: Estimation of blooming date for Prunus yedoensis by means of kinetic method (in Japanese with English abstract). Journal of Agricultural Meteorology, 45, 25-31.

Richardson, A. D., Jenkins, J. P., Braswell, B. H., Hollinger, D. Y., Ollinger, S. V., and Smith, M.-L., 2007: Use of digital webcam images to track spring green-up in a deciduous broadleaf forest. Oecologia, 
152, 323-334.

Saitoh, T. M., Nagai, S., Saigusa, N., Kobayashi, H., Suzuki, R., Nasahara, K. N., and Muraoka, H., 2012: Assessing the use of camera-based indices for characterizing canopy phenology in relation to gross primary production in a deciduous broad- leaved and an evergreen coniferous forest in Japan. Ecological Informatics, 11, 45-54.

Shimizu, Y., and Omasa, K., 2010: Trends in flowering date of Japanese apricot (Prunus mume Sieb. et Zucc.) between 1961 and 2007 (in Japanese with English abstract). Journal of Agricultural Meteorology, 66, 279-288.
Smith, A. R., 1978: Color gamut transform pairs. Computer Graphics, 12, 12-19.

Takagi, M., and Shimoda, Y., 2004: Handbook of Image Analysis. Revised ed. University of Tokyo Press, Tokyo (in Japanese), 1991 pp.

Ueno, K., Isono, J., Imaizumi, F., Inami, A., Kanai, R., Suzuki, K., Kobayashi, H., Tamagawa, I., Saitoh, T. M., and Kondo, H., 2013: Data archive of meteorological data created through the Japanese Alps interuniversity cooperative project (in Japanese with English abstract). Journal of Geography, 122, 638-650. 